\title{
Intervención Urbana Integrada en el centro metropolitano de São Paulo - SP. Estudio de caso Largo Paissandu
}

\author{
Deize Sbarai Sanches Ximenes ${ }^{1}$, Denise Gonçalves Lima Malheiros², \\ Fabio Cesar Moreira Manente ${ }^{3}$ \\ ${ }^{12}{ }^{3}$ Departamento de Arquitetura e Urbanismo, Universidade Paulista - Campus Alphaville, \\ Universidade de São Paulo, São Paulo, Brasil, ${ }^{1}$ IEA USP Instituto de Estudos Avançados da \\ Universidade de São Paulo - Programa Cidades Globais, São Paulo, Brasil. \\ E-mail: 1deizesanches@usp.br, ${ }^{2}$ denisemalheiros@uol.com.br, ${ }^{3}$ fcmanente@gmail.com
}

\begin{abstract}
Resumen. Este trabajo tiene como objetivo presentar un estudio urbanístico integrado en el centro de la ciudad de São Paulo, principal ciudad de Brasil y núcleo de la mayor metrópoli de América del Sur. El proceso de crecimiento de São Paulo definió un área urbanizada difusa con un centro histórico, que, a pesar de poseer una buena infraestructura de transporte y servicios, se caracteriza por la degradación urbana y social, la depreciación del patrimonio construido, la escasez de vivienda y el mal uso de los espacios públicos, reproduciendo el proceso de ocupación verificado en las grandes ciudades latinoamericanas. La recalificación de las zonas centrales deterioradas puede ser un punto de partida para que las ciudades se vuelvan más saludables y equilibradas. Desde esta óptica buscamos identificar un lugar en el centro histórico que presente potencialidades para la propuesta de acciones capaces de recalificar no sólo su área de influencia inmediata, sino que fuera catalizador e irradiador de soluciones más amplias conectadas al territorio metropolitano - el Largo Paissandu. La propuesta de intervención considera cuatro ejes estructurales - Espacio Público, Vivienda, Patrimonio Histórico-Cultural y Movilidad - adoptando la fluidez como estrategia central. Colabora con la ruptura del proceso de degradación, con el aprovechamiento del patrimonio edificado y cultural, con el incentivo al uso habitacional y al uso social de los espacios públicos, además de proponer soluciones para la mejora de la movilidad y accesibilidad.
\end{abstract}

Palabras clave: Intervención urbana integrada, fluidez, espacio público, patrimonio, movilidadcentrales de la ciudad.

\section{Introducción}

El siglo XXI es el siglo de las ciudades y la búsqueda de la construcción de la urbanidad ${ }^{1}$ se constituye en un factor preponderante para obtener ciudades vivas y dinámicas, ciudades para y con las personas; haciendo que las ciudades y los asentamientos humanos inclusivos, seguros, resilientes y sostenibles sean uno de los objetivos de desarrollo sostenible del milenio ${ }^{2}$.

La limitación de la expansión territorial y la densificación de áreas urbanas ya consolidadas nos coloca frente a otra necesidad en las ciudades: la de tener espacios eficientes y multiuso. En ese sentido se vuelven esenciales algunos principios como agregar funciones en el mismo barrio; volver a habitar el centro; situar el empleo más cerca de casa; invertir en corredores verdes y producir conexiones dotadas de carriles bici y aceras de peatones; y el fomento del transporte público.

La mayor parte de la población mundial es urbana y no rural. El crecimiento urbano sigue 
en aceleración, lo que implica la necesidad de revisar los conceptos de planificación y redefinición de prioridades. Brasil no figura entre los países con mayores densidades de población. Sin embargo, en números absolutos es un país muy populoso, pero con una distribución espacial bastante irregular en el territorio. Las grandes ciudades brasileñas crecen de acuerdo con un modelo de ocupación territorial distante, disperso y desconectado, caracterizado por el crecimiento desmedido, fragmentado y no planificado de la mancha urbana.

Buscar soluciones de futuro en la regeneración, tanto de las periferias, como de los centros históricos, mediante intervenciones urbanas que apunten a la mejora ambiental y social de las ciudades con base en patrones de sustentabilidad, que además se constituye en la temática central de este III Congreso ISUF-h, motivó a presentar este estudio urbanístico ${ }^{3}$ desarrollado para un espacio público ubicado en el centro histórico de la ciudad de São Paulo, principal ciudad de Brasil y núcleo de la mayor metrópoli de América del Sur.

\section{Objetivo}

Con el entendimiento de que las ciudades eficientes y equilibradas son las que permiten recalificar sus áreas deterioradas y que mejorar las regiones centrales es el primer paso para tener ciudades más humanas, identificamos un área que presente potencialidades para la proposición de acciones capaces de recalificar no sólo su entorno inmediato, sino también que fuesen catalizadoras e irradiadoras de soluciones más amplias conectadas al territorio metropolitano - el Largo Paissandu.

Así, este trabajo tiene como objetivo presentar un estudio urbanístico integrado con proposición de acciones de recalificación en el centro histórico de la ciudad de São Paulo.

\section{Ubicación y contexto urbano: Largo Paissandu en la Ciudad de São Paulo}

El proceso de crecimiento de la ciudad de São $\mathrm{Paulo}^{4}$ dio lugar a un área urbanizada difusa con un centro histórico que, a pesar de poseer buena infraestructura de transporte y servicios, se caracteriza por la degradación urbana y social, la depreciación del patrimonio construido, la escasez de vivienda y el mal uso de los espacios públicos, reproduciendo el proceso de ocupación verificado en las grandes ciudades latinoamericanas. La ciudad sufre desde hace años los problemas urbanos y sociales generados por el vaciamiento del centro histórico, que antes era conocido por su vocación al entretenimiento -agitación en los teatros, cines, circo y cabarets- que cedieron su espacio a los nuevos centros financieros. Desde el final de los años 1990, el poder público buscó su regeneración, habiendo sido el primero en promover su reocupación, al trasladarse en gran parte a su zona perímetral. Las consecuencias de este proceso son visibles en el abandono de muchos edificios, que actualmente se encuentran deteriorados por falta de mantenimiento con lo que pasaron a ser habitados por familias desprovistas de vivienda. Con un tejido urbano peculiar, se caracteriza por la presencia de espacios públicos con la presencia de innumerables galerías con pasajes internos, pasos peatonales, largos, plazas, cantos centrales y el Valle del Anhangabaú.

\section{El lugar}

El área objeto de intervención está ubicada en el núcleo histórico de la ciudad de São Paulo$\mathrm{SP}$, insertada en el distrito de la República, en la Subprefectura de la Sé - Sub-Sé (Fig. 1). En este distrito viven 62.748 habitantes, de los 514.631 habitantes de la Sub-Sé (Est. IBGE, 2017). Abarca un perímetro de 21 Ha en el entorno de Largo Paissandu. Integra el llamado Centro Viejo, en la rótula central de la ciudad y tiene el Valle del Anhangabaú como uno de los principales referentes como elemento divisor de este territorio. Se caracteriza por una malla urbana consolidada con gran cantidad de inmuebles protegidos por ley y de representatividad por su arquitectura, paisaje y/o historicidad. Hay una red de espacios públicos que potencian el lugar: galerías con fruición en la planta baja, calzadas, calles peatonales, largos y plazas, además de los antiguos cines ubicados en el interior de las cuadras con la posibilidad de 


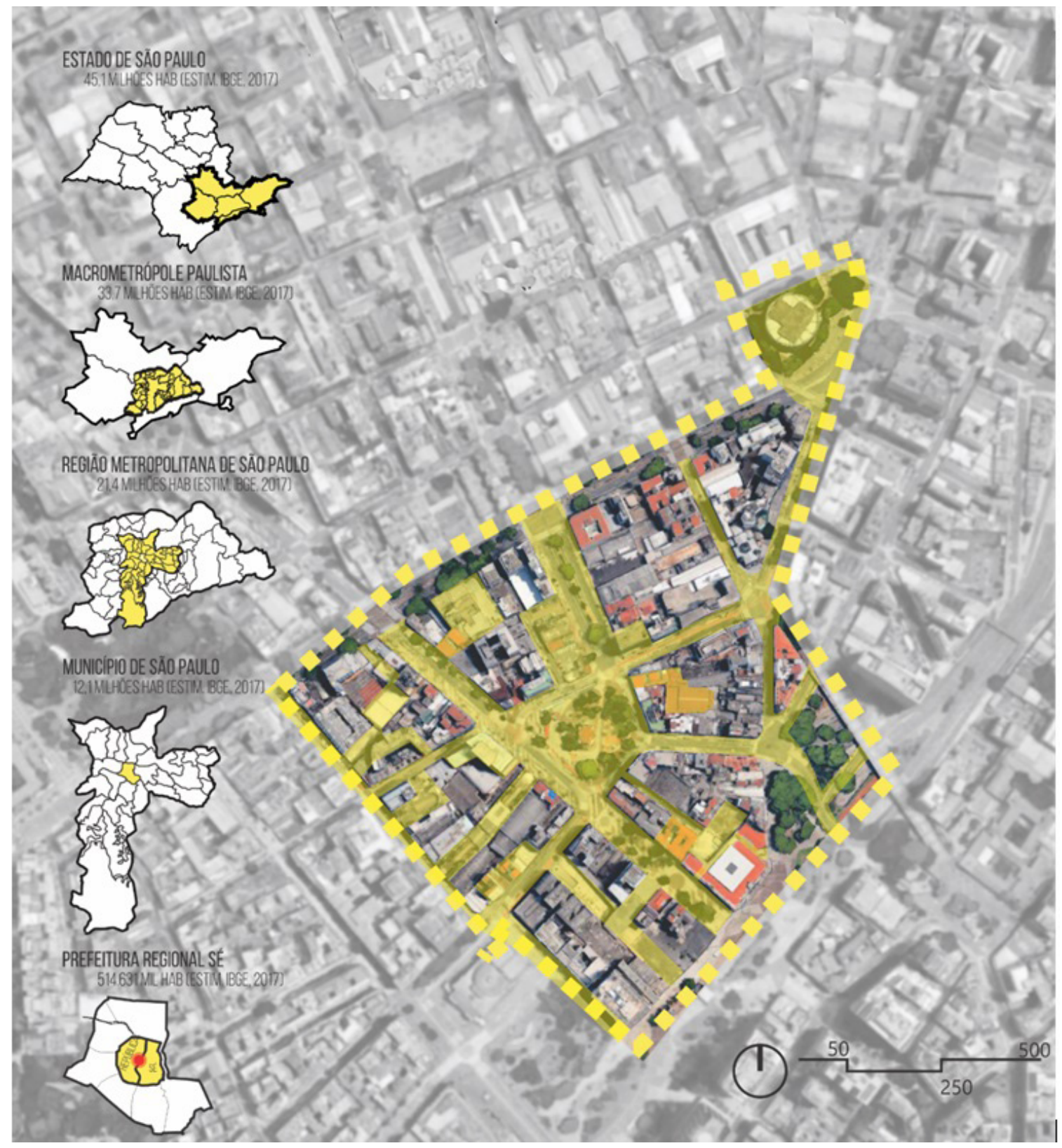

Fig. 1. Área de Intervención: contexto local-metropolitano. Fuente: URBAN21, 2018.

ampliar su acceso por una o más calles. La cuestión habitacional y social es una necesidad prioritaria, teniendo en cuenta la diversidad de personas que habitan ese área, entre las que se incluyen desamparados y refugiados que viven en condiciones precarias. Algunos edificios residenciales están degradados, otros, están junto a inmuebles protegidos por ley o incluso vacíos sin ningún tipo de restauración. Hay ocupaciones que ponen en riesgo la seguridad y la calidad de vida de sus actuales habitantes, además de los peatones que pasan por el lugar. En este perímetro cuatro ejes viales se destacan como estructuradores - la Avenida São João, la Avenida Rio Branco, la Avenida Ipiranga y la Avenida Casper Líbero que lleva a la región de la Luz. Los viaductos Santa Ifigênia y del Chá establecen la conexión entre los distritos Sé y República transponiendo el Valle del Anhangabaú. La accesibilidad se complementa con los paseos exclusivos para peatones. A pesar de que este área está ubicada en una región bien servida de infraestructuras y servicios, presenta un alto grado de degradación. Además, concentra población en situación de vulnerabilidad 
social, ya sea por habitar en las calles o por ocupar $^{5}$ los inmuebles infrautilizados. Por otro lado se verifica una serie de potencialidades de recalificación a través del aprovechamiento del patrimonio edificado y cultural, de los espacios públicos y del incentivo de nuevas actividades económicas.

Las directrices y estrategias de desarrollo de la legislación urbanística vigente ${ }^{6}$ incentivan las iniciativas de economía creativa de carácter solidario y cooperativo, la calificación de los espacios públicos y la revitalización de áreas deterioradas, dando soporte a las acciones definidas en el estudio urbanístico para la recalificación del lugar.

\section{Directrices y estrategias para la recalificación}

La propuesta de intervención considera cuatro ejes estructurales - Espacio Público, Vivienda,

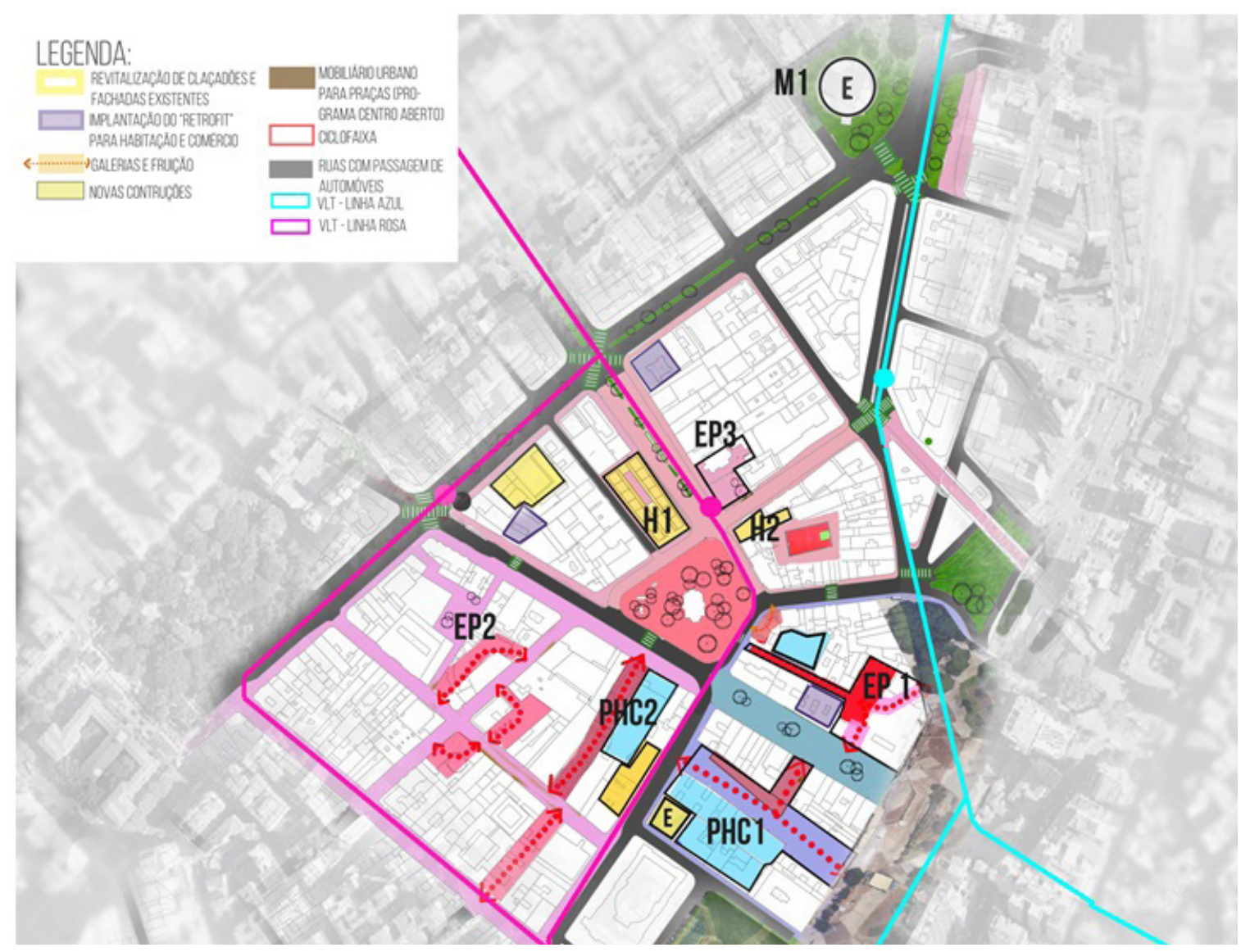

Fig. 2. Propuesta de Intervención. Fuente: URBAN21, 2018.

\section{ESTRATÉGIAS}

ADENSAR:
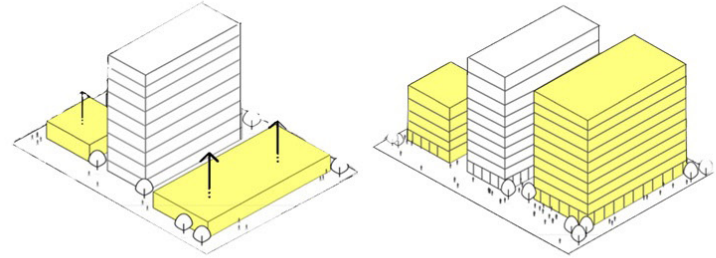

REDESCOBRIR E SE APROPRIAR

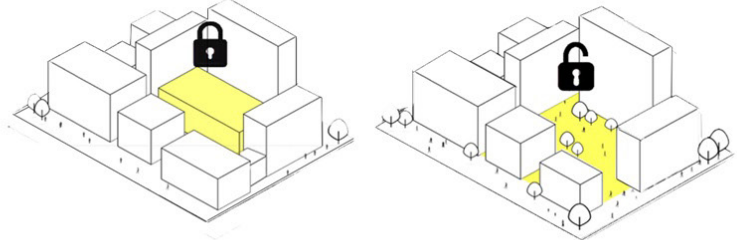

Fig. 3. Directrices y Estrategias para la Recalificación. Fuente: URBAN21, 2018. 
Patrimonio Histórico-Cultural y Movilidad adoptando la fluidez como estrategia central. Se busca minimizar el proceso de degradación, con el aprovechamiento del patrimonio edificado y cultural, con el incentivo al uso habitacional y al uso social de los espacios públicos, además de proponer soluciones para la mejora de la movilidad y accesibilidad.

Las estrategias definidas para los Espacios Públicos apuntan a la integración de las galerías a la red de calzadas y calles peatonales; al aprovechamiento del interior de las cuadras como espacio de uso colectivo, posibilitando la circulación de peatones, la instalación de equipamientos de deporte y de mobiliario urbano que favorezca su utilización para actividades recreativas $\mathrm{y}$ culturales; y la utilización de la planta baja de las edificaciones como una continuidad del espacio público. El tema Vivienda considera la diversidad de los usuarios, con atención a las necesidades y demandas locales y a los varios niveles de renta. Integra las viviendas a los equipamientos sociales que responden a las demandas locales de educación infantil, salud, asistencia social y atención al anciano. Proporciona atención especial a la población vulnerable y de bajos ingresos a través del aprovechamiento de inmuebles infrautilizados. La cantidad significativa de viviendas y el tejido urbano típico de la región central sugiere la valorización del Patrimonio HistóricoCultural para usos diversos, en especial para la vivienda, además de la utilización de las plantas bajas de los edificios públicos protegidos para actividades culturales, artísticas, gastronómicas y otras. Para adecuar la Movilidad al contexto local, se propone disminuir el flujo de tráfico colectivo y de automóviles sugiriendo medidas de transporte público que se vinculen a las terminales de autobuses existentes y la implantación de circuito peatonal.

\section{La propuesta}

Se consideran los cuatro ejes estructurales definidos en el estudio urbanístico - Espacios Públicos, Vivienda, Patrimonio HistóricoCultural y Movilidad - como forma de romper el proceso de degradación y aislamiento existente en este sector del núcleo histórico de la ciudad de São Paulo. Se pretende transformar el Largo Paissandu y su entorno de lugar de paso, parada de autobús y área degradada en un lugar que propicie la permanencia y accesibilidad de las personas. La propuesta se presenta e ilustra a continuación (Fig. 2 y 3 ).

\section{Espacio público}

Se propone la recalificación de los espacios públicos existentes y la apertura de nuevos espacios permeables, salubres y equipados, que promuevan vida urbana día y noche, integrando y acogiendo la diversidad de las necesidades locales. Una estrategia propuesta para los espacios públicos es la integración de las galerías a la malla de calzadas y peatonales. Otraestrategia esel aprovechamiento del interior de las cuadras, actualmente grandes salas de cine sin uso, como espacio de uso colectivo favoreciendo la circulación de peatones, instalación de equipamientos deportivos y mobiliario urbano que permita el desarrollo de actividades culturales. Al abrir esos espacios e integrarlos a la red urbana, trayendo luz, vida y actividades de uso colectivo, se procura dinamizar el lugar propiciando a los visitantes, habitantes y trabajadores de la región opciones de vivencia que amplíen el uso de los espacios locales (Fig. 4).

EP1 Peatonalización de la actual calle Abelardo Pinto y disposición de nuevos usos en las plantas bajas, que se dirigen a la vida nocturna de la región, con bares, cafés y restaurantes, además de una casa de espectáculos que utilizará el área de la antigua sala de exhibiciones del Cine Paissandu. En

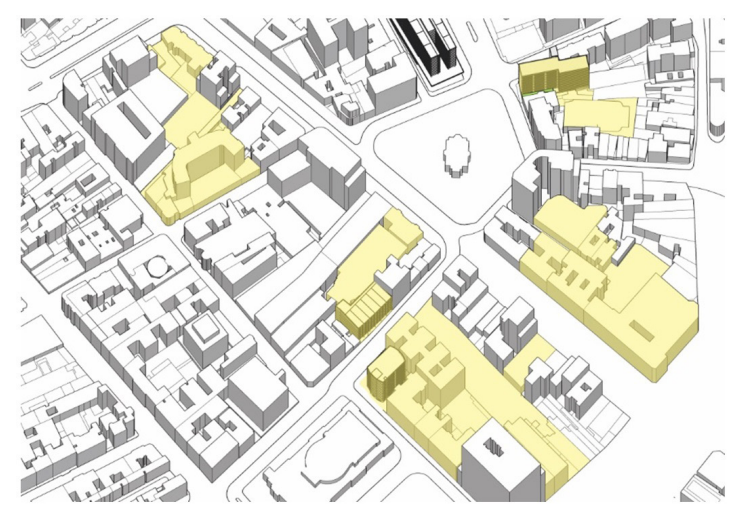

Fig. 4. Espacio público: apropiación del interior de las cuadras. Fuente: URBAN21, 2018 


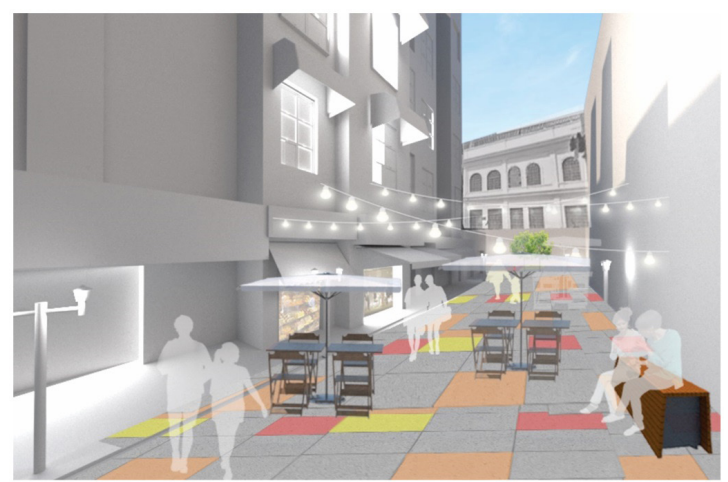

Fig. 5. Espacio público: peatonal en la actual calle Abelardo Pinto. Fuente: URBAN21, 2018.

el patio subutilizado detrás del edificio de Correos, se creará un área con escenario para ferias y eventos al aire libre, que se integrará a la calle peatonal y al Centro Cultural de Correos, integrado con nuevos pasajes a través de la planta baja del edificio hasta la Plaza del Correo y el Bulevar São João, donde el uso actual del inmueble, protegido por ley en esta cuadra, será regularizado y reformado a través de Retrofit, remitiendo al origen histórico y vocación circense del local con uso de pisos coloreados (Fig. 5).

EP2 Utilización del espacio del Cine Ritz en el interior de la cuadra para integrarlo a las áreas comerciales de su alrededor e implantar baños públicos y "plazas de alimentación" promoviendo fruición a la cuadra, que conectará con los paseos ya existentes, que se regeneran en conjunto con las fachadas hoy deterioradas.

EP3 Implantación de una plaza y un memorial en el antiguo Edificio Wilton Paes de Almeida ${ }^{7}$. Esta nueva área verde formará parte de un circuito peatonal, conectando las iglesias y los largos de la zona -Largos Paissandu, Santa Ifigênia e São Bento-, además de la iglesia Luterana en Avenida Rio Branco, con nuevas calles peatonales y recuperación de calzadas ya existentes.

\section{Vivienda}

El tema vivienda responde a la diversidad de sus usuarios con atención a sus necesidades y demandas, especialmente a las de la población más vulnerable y de bajos ingresos. Integra viviendas $\mathrm{y}$ los equipamientos sociales

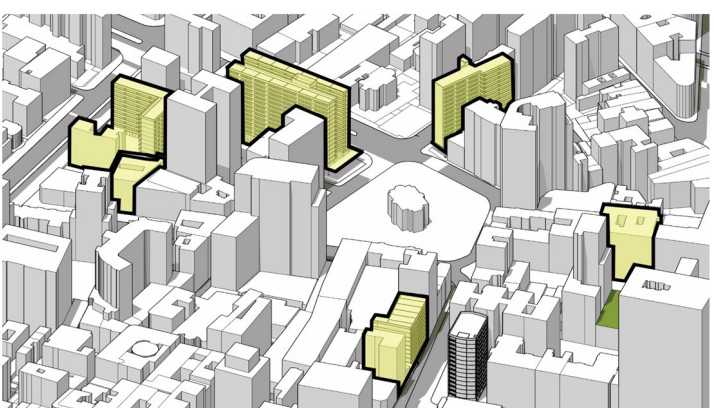

Fig. 6. Vivienda: diversidad para habitar. Fuente: URBAN21, 2018.

atendiendo a las demandas por educación infantil, salud, asistencia social y atención al anciano. Se verifica un amplio potencial de la edificación para su recalificación con posibilidad de densificarla. La problemática local está en la existencia de inmuebles vacíos, infrautilizados o más allá, ocupados de forma precaria, donde hay potencial para su aprovechamiento pensando en la provisión de vivienda social y regularización de su ocupación. Estos inmuebles pueden albergar a la población que actualmente habita en la calle a través de programas de alquiler social a cambio de beneficios a los propietarios de los inmuebles.

La densidad habitacional propuesta se desarrolla en terrenos de interés público utilizando dispositivos legales establecidos en el Plan Director Estratégico, como las Zonas Especiales de Interés Social - ZEIS, la Transferencia de Potencial Constructivo de inmuebles protegidos por ley, la Desapropiación para Fines Urbanísticos y el Parcelamiento, Edificación y Utilización Obligatorios de los inmuebles no edificados, infrautilizados o no utilizados. Se promueve la construcción de edificios habitacionales de tipología de usos mixtos: comercio, servicios y equipamientos.

Además de las nuevas edificaciones, se atenderá a los habitantes de asentamientos informales de la región, con la recuperación de sus inmuebles para poder regularizar la vivienda.

Se observa la existencia de iniciativas inmobiliarias en distritos contiguos, que tienden a expandirse hacia el área de intervención. Se pretende diversificar el perfil habitacional de 


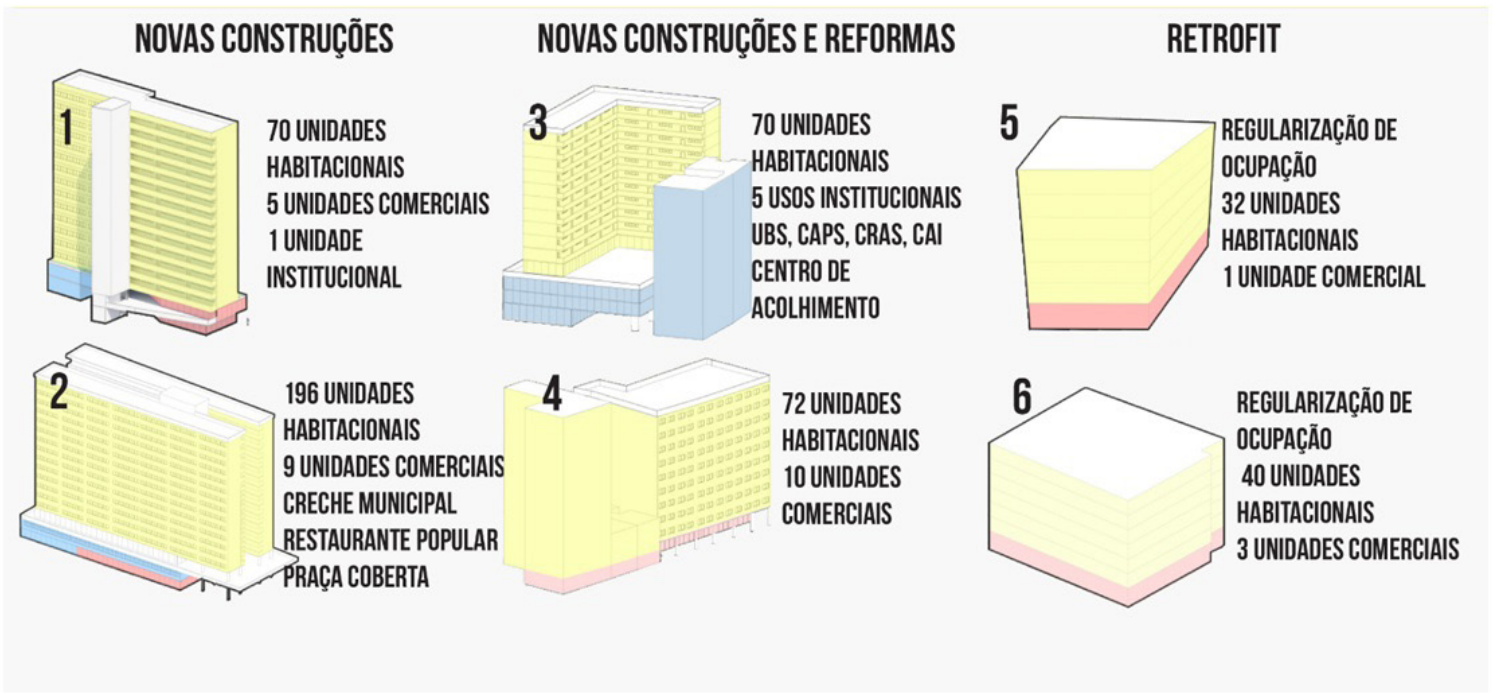

Fig. 7. Vivienda: Tipologías de uso mixto. Fuente: URBAN21, 2018.

forma que las necesidades del público queden cubiertas. El uso de la región del centro metropolitano como espacio para la vivienda debe estar presente en las diversas formas de habitación (Fig. 6 y 7).

H1 Edificio de viviendas para atender la demanda local, destinado a los desamparados de la región. Contiene uso comercial, una plaza cubierta y una unidad de educación infantil, se ubica en ZEIS actualmente utilizado para estacionamientos. Se propone la recalificación de edificios ya existentes para vivienda, siendo uno de ellos Retrofit, con la implantación de una Unidad Básica de Salud y equipos de asistencia social, como el centro de acogida para personas desamparadas, que viven en la calle y que ocupan inmuebles abandonados.

H2 Edificio residencial, en el lugar donde se encontraba el Edificio Wilton Paes de Almeida (que fue gravemente afectado por el incendio) y otro edificio subutilizado por estacionamientos. Posee comercio en las plantas bajas y fruición en su planta baja, dando acceso al centro de la cuadra, originalmente ocupada por el Cine Bandeirantes, que fue abierta para funciones de deporte y ocio, recreación infantil y academia integrada. Es parte de la estrategia de apertura del interior de las cuadras antes ocupadas por cines subutilizados.

\section{Patrimonio Histórico-Cultural}

La cantidad significativa de inmuebles protegidos por ley y el tejido urbano típico de la región central sugiere la valorización del Patrimonio Histórico-Cultural para usos diversos, incluyendo el habitacional, con la utilización de la planta baja de los edificios públicos del patrimonio histórico para actividades culturales, artísticas, gastronómicas $\mathrm{y}$ otras. Hay varios bienes patrimoniales significativos en el entorno. Estos locales fomentan y alientan la circulación de turistas y peatones. Para valorizar y reafirmar el patrimonio local, se propone la readecuación de los inmuebles protegidos por ley $\mathrm{y} / \mathrm{o}$ de representatividad para recalificar este patrimonio histórico-cultural.

PHC1 En la cuadra donde se sitúa el Cine Marrocos, hoy perteneciente a la Secretaría Municipal de Educación (aún sin uso), se propone, además de su puesta en uso por parte de la propia Secretaría, la implantación de una escuela y guardería infantil y de un centro de cultura volcado a inmigrantes y refugiados, que se ubicará en la antigua sala de exhibiciones del cine, y se conectará a la Plaza de las Artes. En la esquina de la Rua Conselheiro Crispiniano con la Plaza Ramos de Azevedo, un nuevo edificiogaraje será erigido en terrenos actualmente 
subutilizados para reubicar las plazas de estacionamiento existentes.

PHC2 Para el Cine Art Palácio, se propone su transformación en escuela de teatro con las actividades integradas en la Plaza de las Artes $^{8}$. En el lugar donde se concentran los estacionamientos que ocupan los inmuebles en área de ZEIS, se proyectan nuevas unidades habitacionales que establecerán su diálogo con la cuadra colindante.

\section{Movilidad}

A escala macro, la intervención se caracteriza por la integración de los sistemas modales -transporte público, automóvil, ciclismo y peatones- considerando los proyectos ya implantados o en estudio por la Administración. El sistema de movilidad propone la adaptación de las cuatro terminales de autobuses existentes -Princesa Isabel, Amaral Gurgel, Bandeira e Parque Dom Pedro II- en multimodales, integrándolos a la línea de Vehículos Ligeros sobre Railes - VLT, a dos nuevos corredores de autobuses y a algunas líneas de autobuses existentes internas al perímetro de estudio, que serán reestructuradas.

Para disminuir el flujo de tráfico colectivo y de automóviles, se sugiere implantar el sistema de vehículos ligeros sobre rieles VLT integrado a las terminales de autobuses existentes, construir edificios-garaje estratégicos e implantar un circuito peatonal interconectando los Largos Paissandu, Santa Ifigênia y São Bento con un futuro itinerario peatonal en la actual Calle Antônio de Godoi y su continuidad a través del Viaduto Santa Ifigênia.

M1 Implantación de edificios-garaje para suplir la demanda de usuarios de transporte individual de la región. La Praça Alfredo Issa, que presenta falta de uso por la población, será recalificada, con mejoras en aspectos paisajísticos e implantación de mobiliário.

\section{Pasos de implementación}

Para viabilizar la intervención, el proyecto fue dividido en tres etapas de implantación:

La primera etapa contempla intervenciones leves y de adaptación de los usuarios al proyecto, con la implementación de las "Calles de Ocio", la composición del marco paisajístico y las medidas de pacificación de tráfico. Se pretende hacer el ambiente más acogedor al uso peatonal y atender a las demandas derivadas de la desactivación de los estacionamientos actualmente ubicados en las plantas bajas de las edificaciones, mediante la construcción de edificios-garaje.

En una segunda etapa, se densifica el área con edificios de uso mixto con viviendas de diversas modalidades que mantendrán la condición de diversidad en el lugar. La apertura del interior de las cuadras y la implementación de equipamientos dedicados a la salud, la educación y el deporte revalorizan la vida pública de la población. La implantación de nuevas calles peatonales y la recalificación de las existentes objetiva la apropiación del espacio público por los peatones.

La tercera etapa introduce el nuevo modal: el vehículo ligero sobre rieles. Se pretende retirar el transporte colectivo pesado sobre ruedas e interconectar las cuatro terminales.

\section{Conclusión}

Este estudio urbanístico para el Largo Paissandu, en el centro metropolitano de São Paulo, demuestra la posibilidad de regeneración de áreas centrales degradadas a través de intervenciones locales que consideren, a partir de un detallada lectura y análisis urbano, las características del lugar, su población, el tejido urbano y el conjunto edificado. Al favorecer la apertura de nuevos caminos en el interior de las cuadras, recuperar los existentes, integrar ambos al sistema peatonal, dialogar con los edificios históricos, reorganizar el flujo de vehículos y estimular el uso habitacional y cultural, la propuesta presentada demuestra que es posible recuperar la urbanidad del espacio público, actualmente perdida, con intervenciones de bajo impacto.

$\mathrm{Al}$ intervenir en el centro de la ciudad con la propuesta de acciones para su recalificación de forma integrada, se extiende el alcance de la intervención a la escala metropolitana como una medida para atenuar los procesos de crecimiento extensivo de las grandes conurbaciones urbanas. 


\section{Agradecimientos}

Este trabajo se ha basado en un proyecto desarrollado en el marco del concurso universitario de urbanismo Urban 21 realizado por la revista PROYECTO con el patrocinio de Alphaville Urbanismo S/A, bajo nuestra orientación. Agradecemos a los alumnos del curso regular de Arquitectura y Urbanismo de la Universidad Paulista - UNIP que integraron el equipo. En especial, a Shayene Juliana de Souza Carneiro y Vítor Godinho Correa dos Santos, integrantes del equipo, agradecemos su colaboración en la redacción de este artículo.

\section{Notas}

$1 \mathrm{El}$ concepto de urbanidad caracteriza lo que es propio de Urbs. Se refiere al modo en que los espacios de la ciudad acogen a las personas. Es una calidad de la forma de la ciudad que repercute en el bienestar de las personas en el espacio público.

2 Estas medidas integran los Objetivos de Desarrollo Sostenible - ODS - de la Agenda 2015 a 2030 de la ONU, constituyendo el ODS 11, que busca promover el desarrollo económico, la inclusión social y la protección ambiental de las ciudades.

3 Este estudio urbanístico fue objeto de un proyecto desarrollado en el marco del Concurso Universitário de Urbanismo Urban 21 celebrado en 2018 por Revista PROJETO con el patrocinio exclusivo de la Alphaville Urbanismo S/A, bajo nuestra orientación.

4 La ciudad de São Paulo, ubicada en la región sudeste del país, es hoy la mayor y principal ciudad de Brasil. Ocupa un territorio de $1521,11 \mathrm{~km}^{2}$, abriendo una población total de más de 12.176.866 habitantes, lo que corresponde a cerca del 5,8\% de la población brasileña. Con su enorme proporción, concentración poblacional, actividades económicas y diversidades, constituye el municipio-núcleo de la mayor aglomeración urbana del país - la Região Metropolitana de São Paulo - RMSP, concentrando alrededor del $56 \%$ de su población.

5 Las ocupaciones son el término dado al obtener la posesión, sin regularidad o medios legales, de inmuebles desocupados y $\sin$ utilización por el propietario original.

6 Plan Director Estratégico del Municipio de São Paulo instituido por la Ley n. 16.050, de 31 de julio de 2014.

7 El Edifício Wilton Paes de Almeida fue un edificio público destinado a oficinas que se quedó sin ser utilizado por largo período. Por este motivo fue ocupado por personas desprovistas de vivienda. Debido a la precariedad de las instalaciones pasó por incendio y derrumbamiento el 01/05/2018 causando la muerte de 7 personas y dejando 291 familias sin hogar.

8 La Plaza de las Artes es una intervención urbana y arquitectónica que consiste en un conjunto de edificios culturales ubicados en la región central de la ciudad de São Paulo.

\section{Referencias}

Campos, Candido Malta; Gama, Lúcia Helena; Sacchetta, Vladimir, organizadores. 2004. São Paulo Metrópole em trânsito: percursos urbanos e culturais. São Paulo: Senac/PMSP.

Frugoli, Heitor. 2000. Centralidade em São Paulo. Trajetórias, Conflitos e Negociações na Metrópole. São Paulo: Cortez/Edusp.

Leite, Carlos. 2016. "Instrumentos Urbanos Inovadores". Revista ARCOweb, 24 de maio de 2016.

Paula, Marilene de; Bartelt, Dawid Danilo, organizadores. 2016. Mobilidade urbana no Brasil: desafios e alternativas. Rio de Janeiro: Fundação Heinrich Böll.

São Paulo (cidade). Prefeitura do Município de São Paulo - PMSP. Plano Diretor Estratégico do Município de São Paulo: lei municipal $\mathrm{n}^{\circ}$ 16.050, de 31 de julho de 2014; texto da lei ilustrado. São Paulo: PMSP, 2015.

Secretaria Nacional de Mobilidade Urbana. Transporte Ativo. Ministério das Cidades, 2016.

Solà-Morales, Manuel de. 1994. "Ações Estratégicas de Reforço do Centro". Revista Domus, $n^{\circ} 759$, pág. 109 a 119. São Paulo.

Solà-Morales, Manuel de. 1993. "Espaços públicos, espaços residuais". Revista Domus, $\mathrm{n}^{\circ} 754$, pág. 147 a 151. São Paulo.

SP Urbanismo. Projeto de Intervenção Urbana Setor Central. Prefeitura do Município de 
São Paulo, 2018.

Villaça, Flávio. 2001. Espaço intra-urbano no

Brasil. São Paulo: Studio Nobel $2^{a}$ Edição. 